\title{
Investigating the Associations among Overtime Work, Health Behaviors, and Health: A Longitudinal Study among Full-time Employees
}

\author{
Toon W. Taris $\cdot$ Jan Fekke Ybema . \\ Debby G. J. Beckers • Marieke W. Verheijden • \\ Sabine A. E. Geurts • Michiel A. J. Kompier
}

Published online: 3 June 2010

(C) The Author(s) 2010. This article is published with open access at Springerlink.com

\begin{abstract}
Background It has often been suggested that high levels of overtime lead to adverse health outcomes. One mechanism that may account for this association is that working overtime leads to elevated levels of stress, which could affect worker's behavioral decisions or habits (such as smoking and lack of physical activity). In turn, this could lead to adverse health.

Purpose The present study examined this reasoning in a prospective longitudinal design. Data from the prospective 2-year Study on Health at Work $(N=649)$ were used to test our hypotheses.

Methods Structural equation analysis was used to examine the relationships among overtime, beneficial (exercising, intake of fruit and vegetables) and risky (smoking and drinking) health behaviors, and health indicators (BMI and subjective health).

Results Working overtime was longitudinally related with adverse subjective health, but not with body mass.
\end{abstract}

T. W. Taris

Utrecht University,

Utrecht, The Netherlands

T. W. Taris • D. G. J. Beckers • S. A. E. Geurts • M. A. J. Kompier Behavioral Science Institute, Radboud University Nijmegen,

Nijmegen, The Netherlands

J. F. Ybema $\cdot$ M. W. Verheijden

TNO Quality of Life,

Hoofddorp/Leyden, The Netherlands

T. W. Taris $(\bowtie)$

Department of Social and Organizational Psychology,

Utrecht University,

P.O. Box 80.140 , NL-3508 Utrecht, The Netherlands

e-mail: T.Taris@uu.nl
Moreover, working overtime was associated with lower levels of physical activity and intake of fruit and vegetables, but not with smoking and drinking. Finally, higher levels of risky and lower levels of beneficial health behaviors were longitudinally associated with ill health.

Conclusions The relation between overtime and ill health is partly accounted for by the unhealthy lifestyle in which overworkers tend to engage. However, a direct longitudinal effect of overtime on health suggested that the effects of overtime on health may also partly be due to the sustained physiological activation that results from working overtime. Whereas working a moderate amount of overtime does not usually entail major health risks, these will increase with increasing overtime.

Keywords Overtime $\cdot$ Health $\cdot$ Health-risk behavior

\section{Introduction}

Long working hours and overtime work are common phenomena in today's industrialized countries [1,2]. Whereas most overworkers prefer to reduce their overtime hours [3], the high prevalence of overtime work has led to concerns about the impact of working time on worker health. To date, five major reviews on the relation between long working hours and worker health have been conducted [4-8]. Overall, these show that although the evidence for an association between overtime work and adverse health is not always consistent and may vary with the type of outcome under consideration, there are indications that particularly excessive overtime work poses a serious health risk [9].

Previous research and theorizing has suggested two mechanisms that could account for the link between 
overtime work and health [10]. First, high levels of overtime may lead to lack of recovery, in turn resulting in adverse health and well-being. Second, the effect of overtime work on worker health could operate through the behavioral decisions and habits (i.e., lifestyle behaviors) of workers, such as smoking, high levels of alcohol consumption, lack of physical activity, and a high intake of saturated fat and calories. Unfortunately, to date few studies have examined the association between overtime hours and worker health in large-scale longitudinal designs, meaning that at present little can be said about the degree to which the behavioral lifestyle mechanism accounts for the association between overtime work and worker health. Therefore, the present study investigated whether the behavioral lifestyle mechanism could account for the association between overtime and health, using a prospective longitudinal design.

\section{Overtime, Recovery and Health}

The physiological recovery mechanism proposes that effort expenditure is associated with short-term physiological and psychological costs (e.g., fatigue and accelerated heart rate; [11]). Normally, these costs are reversible: after a break from work, psychobiological systems will return to a baseline level (recovery, [12]). Recovery will usually occur after a short respite from work, but may be incomplete under certain circumstances. The worker, not fully recovered from the previous work day, must then invest additional effort to perform adequately during the next working period. This results in an increased intensity of negative load reactions [13], demanding yet more of the subsequent recovery process. Thus, a process of accumulation of negative load effects sets off, which may ultimately result in chronic health problems such as prolonged fatigue, chronic tension, etcetera [13, 14]. Following this reasoning, working overtime may have unfavorable effects for worker health and well-being. Recovery from work normally occurs during after-work hours, during weekends, and longer periods of respite (e.g., holidays, [15]). Obviously, working overtime on the one hand increases the duration of being exposed to job stressors (higher effort expenditure). On the other hand, it decreases the time available for recovery from work [16]. Thus, working overtime is potentially hazardous in that it increases the chances that one will be unable to recover from the negative load effects built up during the normal working day adversely affecting worker health.

\section{Overtime, Behavioral Lifestyle Patterns, and Health}

Previous research has frequently documented the relations between overtime and ill health [4-8], but the interpretation of this relationship is as yet unclear. The behavioral lifestyle mechanism $[8,10]$ proposes that the effect of overtime work on worker health operates via behavioral decisions or habits of people exposed to work stressors, such as working overtime [17]. These choices or habits may involve taking health risks, such as smoking, lack of physical activity, and a high intake of saturated fat and calories [10]. Basically, adverse health behaviors are construed as a response to environmental challenges such as long working hours that may culminate in behavioral modification [18]. For example, job strain may increase the consumption of fatty and sweet foods [19], whereas intake of fruits and vegetables may be reduced [20]. High levels of overtime work are also potential barriers to physical activity, restricting the time available for non-work activities [21]. To the degree that working overtime induces stress, smoking and drinking could be used as means to alleviate job stress [18, 22].

Siegrist and Rödel [10] reviewed the evidence for the proposition that high levels of work stress result in healthrisk behavior, finding that (a) cigarette smoking was not consistently related to work stress, (b) there was at least partial support for a role of work stress in heavy alcohol consumption in the longitudinal studies examining this relationship, and (c) the evidence on the relationship between body weight and work stress was inconclusive (note that they did not study physical activity as a lifestyle factor). They concluded that "... at least some of the burden of disease attributable to a health-adverse psychosocial work environment is explained by an unhealthy lifestyle, in particular heavy alcohol consumption, overweight, and cigarette smoking" (p. 479).

\section{The Present Study}

The findings discussed above suggest that (a) high levels of overtime work are related to adverse health outcomes and (b) that this relationship may partly be accounted for by assuming that working overtime changes workers' patterns of health-related behaviors. Of course, working overtime may affect health in the long run both directly (through lack of physiological recovery) and indirectly (via an altered behavioral lifestyle; [10]).

The current study focuses on the behavioral lifestyle mechanism using a 2-year prospective design. We distinguish between two types of health indicators, subjective health and body mass index (BMI). Overweight or weight gain is considered a proxy measure of exposure to a sedentary lifestyle and unhealthy diet, as these conditions often cluster among individuals [10]. As overweight is clearly a health-risk factor [18] and because workers will be aware of this, we expect a negative lagged association between BMI and subjective health (hypothesis 1). More- 
over, the physiological recovery mechanism proposes that the degree to which one works overtime is directly related to both health outcomes. We therefore expect a direct negative effect of overtime on subjective health (hypothesis 2a) and a direct positive effect of overtime on BMI (hypothesis 2b). Further, the behavioral lifestyle mechanism assumes that adverse health behaviors (smoking, alcohol consumption, low intake of fruit and vegetables, and lack of physical activity) will be longitudinally related to high BMI (hypothesis 3a) and low subjective health (hypothesis 3b), and that these adverse health behaviors will be associated with overtime, such that overtime workers will generally display higher levels of adverse health behaviors than others across time (hypothesis 4). Figure 1 summarizes the hypotheses to be tested graphically. In the analyses this model is extended with lagged relationships between the time 1 and time 2 measures of all respective concepts.

\section{Method}

\section{Participants}

Data from the prospective 2-year Study on Health at Work were used $[23,24]$. The sample was drawn from an online research panel including about 100,000 participants from the Dutch population. The majority of the panel members were recruited by inviting participants in other, nationally representative and non-internet-based research to join the online panel. Panel members are contacted twice a month for voluntary participation in internet-based research. The quality of the panel is guaranteed by periodically comparing sample characteristics (including sex, age, level of

Time 1

Time 2

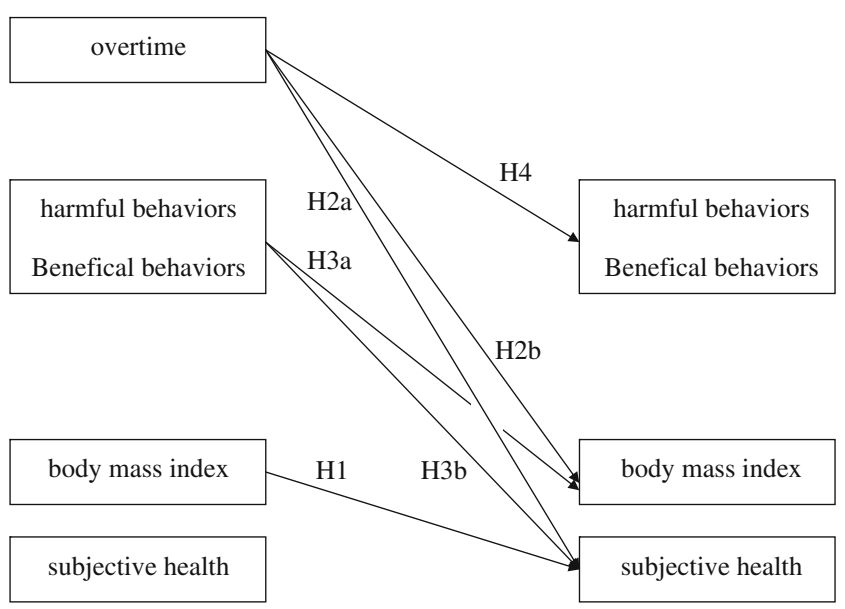

Fig. 1 Overview of the study hypotheses for the associations among overtime work, harmful and beneficial behaviors, and health indicators (body mass index and subjective health). $H x$ refers to hypothesis $\mathrm{x}$ in the text education, marital status, profession, and income) to analogous figures for the Dutch population, as available from the Dutch Census [25].

For the first study wave (T1) 3,100 employees were randomly selected from the online panel. They were invited by email to complete an online questionnaire addressing work characteristics, outcomes, and working times $(80.8 \%$ response, $N=2,502$ ) completed the questionnaire. Selected characteristics of the participants (age, gender, labor market sector, level of education, and ethnicity) were compared to those of the general Dutch employee population as available from the Dutch census. This comparison revealed that non-Western minorities and lower-educated were underrepresented in the sample: the T1 sample included only $7 \%$ immigrants as compared to $16 \%$ for the population, whereas $38 \%$ of the sample held a college or university degree, as compared to $27 \%$ of the population. In other respects, the T1 sample was very similar to the Dutch working population (i.e., the difference between the categories of age, gender, and labor market sector as available for the sample deviated on average $1.6 \%$ from the corresponding population figures) [23].

Two years later (T2), these participants were invited to take part in a follow-up to this study (74.7\% response, $N=$ 1,869). Comparison of the time 1 scores of the time 2 respondents on the study variables to the scores of those who participated at time 1 but not at time 2 revealed that participants with low scores on subjective health and education were slightly more likely to have dropped out of the study. In other respects, no significant differences between respondents and non-respondents were found.

From this sample $(N=1,896)$, we selected the participants who (a) worked full-time at both occasions (i.e., the number of working hours according to their contracts was at least $36 \mathrm{~h}$ per week, leading to a sample of 929 participants), and (b) did not change employers during the 2-year study interval (resulting in a final sample of 649 participants). The average age of the participants was 40.9 years ( $\mathrm{SD}=9.2$ years); $84 \%$ was male; $32 \%$ had a college education, and $14 \%$ held a university degree. The mean number of overtime hours was $5.1 \mathrm{~h}, \mathrm{SD}=6.3 \mathrm{~h}$. About a third of the participants $(33.2 \%, N=215)$ did not work overtime at all. The majority $(54.2 \%, N=352)$ worked low to moderate overtime (1-10 h per week). The remainder $(12.6 \%, N=82)$ spent each week on average at least $11 \mathrm{~h}$ on working overtime.

\section{Measures}

Health The study included two indicators of worker health. First, subjective health was measured as the average score on two items, namely "how would you evaluate your health" (1="bad", 5="excellent") and "how would you 
evaluate your physical health in general" (1="bad", $4=$ "good"). After rescaling the latter item to a five-point format, both items were averaged (rs were 0.56 and 0.58 for time 1 and time 2, respectively, ps $<0.001$ ). Further, the BMI was computed for both occasions, dividing the participant's weight in kilos by their squared length in meters.

Lifestyle measures Four lifestyle measures were included. Physical activity was measured as the number of days per week at which the participants were physically active during at least $30 \mathrm{~min}$, either at work or in their leisure time, as recommended by the Dutch Health Council [26]. Intake of fruit and vegetables was measured as the number of days at which the participants consumed at least $100 \mathrm{~g}$ of vegetables and at least two pieces of fruit; rs were 0.38 and 0.33 for time 1 and time 2 , respectively, ps $<0.001$.

As habits like smoking and drinking are usually already initiated in young adulthood, the relationship between psychosocial working conditions and current smoking and drinking is likely to be reflected in smoking and drinking intensity rather than whether one smokes/drinks [18]. Consistent with this reasoning, smoking was measured as the number of cigarettes the participants on average smoked per day (non-smokers smoked zero cigarettes per day), and drinking was coded as the average number of glasses of alcoholic beverages consumed per week.

In order to examine the associations among these lifestyle factors, additional factor analyses were conducted. Exploratory factor analysis with varimax rotation on the four time 1 lifestyle behaviors revealed two factors with an Eigenvalue of $>1.00$, accounting for $58.8 \%$ of the variance in the four measures. The two harmful health behaviors (smoking and drinking) loaded on one factor (standardized loadings were 0.76 and 0.72 , respectively) whereas the two beneficial health behaviors (physical activity and intake of fruit and vegetables) loaded on the other (loadings were 0.79 and 0.75 , respectively). This pattern was replicated for time 2 using confirmatory factor analysis [27]. The model in which the four behaviors loaded on a single latent dimension did not fit the data well, chi-square $(\mathrm{df}=2, N=$ $649)=13.41$, Root mean squared residual $($ RMSEA $)=$ 0.093. In contrast, a model with two correlated latent factors (with the two harmful behaviors loading on one factor, and the two beneficial behaviors on the other) fitted the data very well, chi-square $(\mathrm{df}=1, N=649=3.74$, ns, RMSEA $=0.065$ ).

On the basis of these findings, we created two variables (one for each time point) representing beneficial health behaviors as the average of the number of days per week on which the participants (a) had sufficient physical activity and (b) ate enough fruit and vegetables (range 1-7). In order to standardize the range of the variables representing the harmful health behaviors (smoking and drinking), these were first trichotomized. In both cases, a zero score was assigned to those participants who did not smoke or used alcohol. We further distinguished among those who smoked and used alcohol less often than average (as computed across those who smoked and used alcohol), versus those who smoked and used alcohol more often than average. For both time points, the cutoff values were the same (smoking: $0=$ "does not smoke"; $1=$ "smokes one to nine cigarettes a day"; $2=$ "smokes $\geq 10$ cigarettes a day"; drinking: $0=$ "does not use alcohol"; $1=$ "drinks one to five glasses per week"; $2=$ "drinks $\geq 6$ glasses per week"). We then computed two variables (one for each time point) representing the harmful health behaviors as the sum of the variables representing smoking and drinking behavior $(0=$ "neither smokes nor drinks alcohol", $4=$ "smokes and drinks more than the average smoker/drinker").

Overtime The number of hours worked overtime was computed by subtracting the number of hours worked according to one's contract from the average number of actual working hours.

Control variables In the analyses, we controlled for job demands and job control, as measured at time 1. Both concepts were measured using four-item adaptations of well-validated scales [28]. A typical item of the job demands scale is "Do you have to work very fast" ( $1=$ "never", $4=$ "always", alpha was 0.78$)$. A typical item of the job control scale is "Can you decide for yourself how you do your work" (1="never", 4="always", alpha was $0.80)$. Finally, participant gender, age, and a seven-category measure of level of education were added as control variables.

\section{Statistical Analysis}

Table 1 presents the correlations, means, and standard deviations for the study variables. The data were analyzed using structural equation modeling (SEM) as implemented in the LISREL 8.30 program [27]. SEM is in many respects similar to ordinary regression analysis, in that it tests the associations between a (set of) criterion variable (s) and various predictor variables. The interpretation of the findings obtained using SEM is roughly analogous to those obtained in regression analysis: upon request, the program provides standardized regression estimates for the relations between pairs of variables that vary between 0 (no association) and \pm 1 (perfect association). SEM requires that researchers specify a model for the expected relations among the study concepts. A range-of-fit 
Table 1 Means, standard deviations, and correlations for the study variables $(N=649)$

\begin{tabular}{|c|c|c|c|c|c|c|c|c|c|c|}
\hline Variables & 1 & 2 & 3 & 4 & 5 & 6 & 7 & 8 & 9 & \\
\hline \multicolumn{11}{|l|}{ Time 1} \\
\hline 1 & Body mass index & 1.00 & & & & & & & & \\
\hline 2 & Subjective health & -0.36 & 1.00 & & & & & & & \\
\hline 3 & Harmful behaviors $^{\mathrm{a}}$ & 0.08 & 0.01 & 1.00 & & & & & & \\
\hline 4 & Beneficial behaviors ${ }^{b}$ & -0.06 & 0.17 & 0.01 & 1.00 & & & & & \\
\hline 5 & Overtime hours & -0.04 & -0.07 & -0.04 & -0.08 & 1.00 & & & & \\
\hline \multicolumn{11}{|l|}{ Time 2} \\
\hline 6 & Body mass index & 0.89 & -0.33 & 0.12 & -0.06 & -0.04 & 1.00 & & & \\
\hline 7 & Subjective health & -0.30 & 0.67 & 0.03 & 0.18 & -0.09 & -0.31 & 1.00 & & \\
\hline 8 & Harmful behaviors $^{\mathrm{a}}$ & 0.11 & 0.02 & 0.84 & 0.04 & -0.03 & 0.14 & 0.02 & 1.00 & \\
\hline \multirow[t]{3}{*}{9} & Beneficial behaviors $^{\mathrm{b}}$ & -0.05 & 0.15 & 0.03 & 0.40 & -0.13 & -0.06 & 0.16 & 0.02 & 1.00 \\
\hline & $M$ & 26.30 & 2.27 & 1.65 & 1.38 & 5.06 & 26.56 & 2.24 & 1.62 & 1.46 \\
\hline & SD & 4.12 & 0.66 & 1.15 & 0.66 & 6.33 & 4.28 & 0.65 & 1.15 & 0.62 \\
\hline
\end{tabular}

Correlations of $>0.08$ are significant at $p<0.05$

${ }^{\mathrm{a}}$ This index includes smoking behavior and alcohol intake

${ }^{\mathrm{b}}$ This index includes physical activity and intake of vegetables and fruits

statistics indicates whether the model as a whole fits the data acceptably well, that is, whether the difference between the observed correlation matrix (presented in Table 1) and the matrix as reproduced using the estimates generated on the basis of the model that was tested: smaller differences indicate better model fit. In the present study, model fit was assessed using the chi-square test statistic as well as the RMSEA. Values of 0.05 and lower signify acceptable model fit [29].

The model presented in Fig. 1 fitted the data well, $\chi^{2}$ $(N=649, \mathrm{df}=7)=16.18, \mathrm{RMSEA}=0.045$. However, none of the control variables were significantly related to the outcome variables. Therefore, the model was rerun after omitting these variables, resulting in a well-fitting model, $\chi^{2}(N=649, \mathrm{df}=7)=14.60, \mathrm{RMSEA}=0.041$. After omitting several other non-significant effects from this model, the final model fitted the data even better, $\chi^{2} \quad(N=649$, $\mathrm{df}=11)=15.09$, RMSEA $=0.024$.

\section{Results}

Table 2 presents the findings for the final model. This table shows that the time 1 measures of the concepts were significantly correlated with the time 2 measures of the same concepts, denoting high across time stability; only for beneficial health behaviors (i.e., physical activity and intake of fruits and vegetables) we found a relatively low effect of $0.39, p<0.001$. The other effects are of more interest, and Fig. 2 present these graphically. For simplicity, the time 1 to time 2 stability effects have been omitted from the figure for all concepts.

Hypothesis 1 proposed a negative effect of BMI on subjective health. This hypothesis was supported by a negative lagged effect of time $1 \mathrm{BMI}$ on time 2 subjective health (a standardized effect of $-0.08, p<0.01$; hypothesis 1 supported). The behavioral lifestyle mechanism proposes that health behaviors will be related to later BMI and subjective health. The two health behaviors distinguished in this study retained different relationships with the two indicators of health. Whereas beneficial health behaviors at time 1 were positively related to subjective health at time 2 (an effect of 0.06, $p<0.05$ ), the harmful behaviors at time 1 were associated with higher BMI at time 2 (an effect of $0.04, p<0.05$; hypotheses $3 \mathrm{a} / 3 \mathrm{~b}$ partly supported). Further, high levels of overtime at time 1 were expected to be associated with higher levels of adverse health behaviors at time 2 . High levels of overtime were indeed longitudinally associated with low levels of beneficial health behaviors (physical activity and intake of fruits and vegetables), but not with harmful health behaviors (smoking and drinking) (hypothesis 4 partly supported).

These findings provide some evidence for the behavioral lifestyle mechanism, proposing that high levels of overtime will result in an unhealthy lifestyle, in turn leading to ill health. However, this does not mean that our findings discredit the physiological recovery mechanism in that time 1 overtime was not only indirectly (via the beneficial health behaviors) but also directly related to time 2 subjective health (a standardized effect 
Table 2 Standardized maximum likelihood estimates for the final model $(N=649)$

\begin{tabular}{|c|c|c|c|c|}
\hline & $\mathrm{T} 2$ harmful behaviors ${ }^{\mathrm{a}}$ & $\mathrm{T} 2$ beneficial behaviors ${ }^{\mathrm{b}}$ & $\mathrm{T} 2$ Body mass index & $\mathrm{T} 2$ subjective health \\
\hline T1 overtime hours & & $-0.10 * *$ & & $-0.06^{*}$ \\
\hline $\mathrm{T} 1$ harmful behaviors ${ }^{\mathrm{a}}$ & $0.84 * * *$ & & $0.04 *$ & \\
\hline T1 beneficial behaviors ${ }^{\mathrm{b}}$ & & $0.39 * * *$ & & $0.06^{*}$ \\
\hline T1 body mass index & & & $0.88 * * *$ & $-0.08 * *$ \\
\hline T1 subjective health & & & & $0.63 * * *$ \\
\hline$R^{2}$ & 0.70 & 0.17 & 0.79 & 0.46 \\
\hline
\end{tabular}

$\chi^{2}(N=649, d f=11)=15.09$, RMSEA $=0.024$

${ }^{a}$ This index includes smoking behavior and alcohol intake

${ }^{\mathrm{b}}$ This index includes physical activity and intake of vegetables and fruits

${ }^{*} p<0.05,{ }^{* *} p<0.01$, and ${ }^{* * *} p<0.001$

of $-0.06, p<0.05$, hypothesis 2 a supported). However, there was no direct effect of time 1 overtime on time 2 BMI (hypothesis $2 \mathrm{~b}$ not supported).

\section{Discussion}

Past research has frequently related overtime to ill health [4-9], but the mechanisms accounting for this relation have been studied less extensively. The present study examined the effects of overtime and beneficial and harmful lifestyle behaviors (cf. 10, 18) on two health indicators (BMI and subjective health) in a two-wave prospective longitudinal study. The three most interesting findings of this research were the following. First, we found that overtime leads to lower levels of beneficial

Time 1

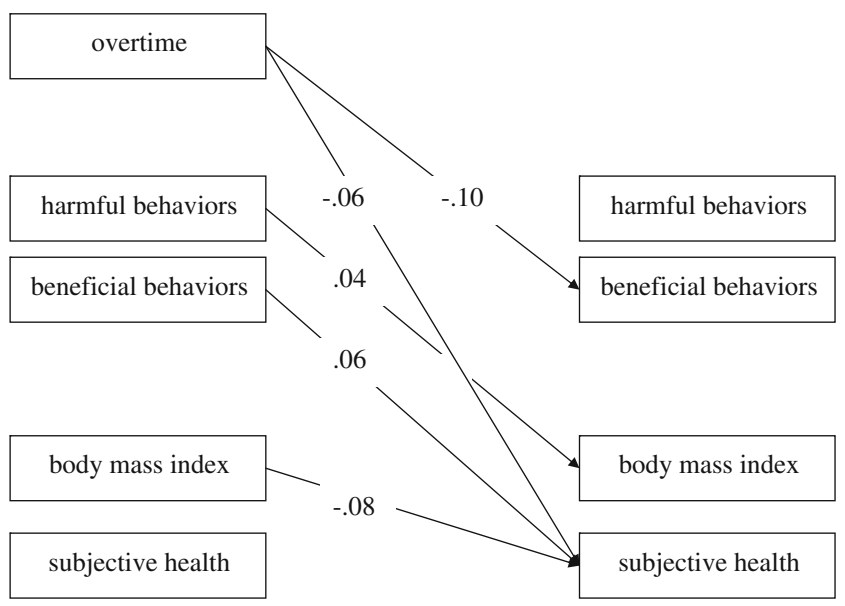

Fig. 2 Longitudinal associations among overtime work, harmful and beneficial behaviors, and health indicators (body mass index and subjective health; all effects significant at $p<0.05$ ). Full results are given in Table 2 health behaviors (physical activity and intake of fruits and vegetables); as these behaviors are longitudinally connected to higher levels of subjective health, high levels of overtime work are indirectly associated with lower levels of subjective health. This pattern of effects supports the behavioral lifestyle mechanism $[10,21,30]$. Note that our two-wave design does not allow us to conclude that we have shown that the relationship between overtime and subjective health is actually mediated by beneficial health behaviors; for this at least three waves of data are needed [31].

Second, high levels of overtime were also directly associated with low levels of subjective health (the underlying correlation was $-0.09, p<0.05$ ); this longitudinal effect remained significant after controlling for health behaviors and body mass index. Thus, the lifestyle factors included in the present research do not fully account for the relationship between overtime and health, suggesting that other unmeasured factors are responsible for part of the effect of overtime on health. Current theorizing and findings propose that these other factors may include psychophysiological factors and lack of recovery [10, 13, 14], emphasizing the need for future research to test the psychophysiological mechanism discussed in the introduction as well.

Third, the beneficial and harmful health behaviors were differentially related to both overtime and the two health outcomes included in this study. The strongest findings were obtained for the beneficial health behaviors; these were significantly associated with both overtime and subjective health (but not with body mass index). Conversely, the harmful health behaviors were only associated with body mass index. This pattern of effects partly replicates previous findings. e.g., Siegrist and Rödel concluded that smoking and body weight were not consistently related to stress [10], which speaks against the hypothesis that overtime (as a source of stress) 
relates to smoking and BMI. Others found that whereas stressed workers were not more likely to use alcohol or to smoke, they were less physically active than others [30]. Similarly, Lallukka et al. reported that high levels of job strain were associated with lower levels of physical activity among males, but not with higher levels of smoking or drinking [18]. Thus, overtime and job strain are primarily related to lower levels of beneficial health behaviors, whereas the evidence for relations with harmful health behaviors is less consistent.

One explanation for this intriguing finding may be that harmful health behaviors like smoking and drinking are usually initiated in young adulthood, and have a relatively strong habitual and even addictive component [18]. This implies that these behaviors will be related to many other factors besides work stress, and may only weakly covary with the latter. This will definitely make it more difficult to detect effects of working overtime on such behaviors. Moreover, beneficial and harmful behaviors differ regarding the effort they require. Whereas smoking or drinking requires little additional time and effort (for example, smoking can easily be done while being involved in other activities), especially being physically active requires considerably more time and effort. This reasoning explains why working overtime (as an activity that requires much effort and time) is related to beneficial rather than to harmful health behaviors - overworkers neither have the opportunity nor the energy to engage in beneficial health behaviors. This could also explain previous findings that both working males and females generally prefer to reduce their overtime work [3]; working overtime simply takes away much time that they would prefer to spend on other activities.

Regarding the differential associations among the health behaviors and the health outcomes, feelings of being healthy may respond more readily to beneficial health behaviors than to harmful health behaviors. Previous research has shown that exercising has positive consequences for mood and general well-being, an effect that may well generalize to subjective health [32]. Conversely, the effects of smoking and drinking on health may only become noticeable after a period of prolonged exposure, and the 2-year interval employed in the present study may have been too short for detecting such effects [33]. Regarding the lack of effect of exercising and intake of fruit and vegetables on body mass, it should be noted that the present set of participants were not particularly obese $\left(M_{\mathrm{BMI}}=26.6\right.$ at time 1$)$. Thus, it is unlikely that a substantial proportion of these workers was exercising or dieting with the aim of losing weight. Of course, intake of fruit and vegetables does not imply that one will lose weight; similarly, high levels of physical activity may well be compensated for by eating calorie-rich snacks and taking sugared sports drinks. All in all, there is no reason to assume that all health-related behaviors are related in a similar way to all health outcomes; rather, it is likely that the mechanisms linking behaviors to outcomes depend on the nature of both the health behaviors under study and the health outcomes involved. This reasoning could also account for the fact that previous findings on the relations among overtime, health behaviors and health outcomes tend to be weak and ambiguous $[8,10]$.

\section{Study Limitations}

The main limitations of this study are the following. First, the present study utilized data from a nationally representative group of Dutch full-time employees. Consequently, although most participants (66.8\%) worked some overtime hours each week, the number of excessive overtime workers (i.e., those participants for which we would expect the strongest effects of overtime on lifestyle and health) was relatively small, restricting the variance of our overtime measure. This implies that the effects reported in the present study are conservative estimates of the effects of overtime on the study outcomes, and that these effects would have been stronger if the sample had included larger numbers of excessive overworkers.

Further, the current study included only a limited number of health behaviors (i.e., smoking, drinking, physical activity, intake of fruit and vegetables). Although these concepts have often been related to health, it does not necessarily follow that all relevant behaviors were included in this study. For example, it would seem likely that intake of unhealthy food is at least as important a determinant of body mass index and subjective health as exercising or smoking. This concern means that the findings of the present study cannot be generalized beyond the behaviors included - for other behaviors, other findings may be obtained. Be that as it may, the present study included the behaviors that are currently deemed most important for health and well-being, judging from previous research on the associations among overtime, lifestyle, and health $[8$, 10, 18].

Finally, the present findings were based on a longitudinal design employing a 2-year interval. This means that the findings cannot be generalized to other time intervals, as the magnitude of effects tends to depend on the interval between the study waves $[33,34]$. Some of the health behaviors included in the present study may only affect health after a substantial period of time has elapsed (e.g., smoking), whereas the effects of other behaviors may appear at shorter notice. Similarly, the effects of working overtime on relatively stable health behaviors (such as smoking and drinking, for which a 0.84 stability coefficient was obtained, cf. Table 1) and health may require more than 2 years to manifest themselves. Again, 
this reasoning implies that the effects reported here are conservative estimates of their true magnitude. Also note that this does not imply that the weak-to-moderate effects reported in the present study are void of practical relevance; in the long run, even weak effects of overtime on health behaviors or of these behaviors on health will become clearly visible [34].

\section{Study Implications}

The most important scientific implication of the current study is that our findings underline the need for a comprehensive theoretical framework that relates overtime to health behaviors and health indicators. Like previous research $[10,18,30]$, the present findings suggest that the relations among these concepts are complex and may depend on both the nature of the health behaviors under study and the health outcomes considered. Our study provided indications that researchers should distinguish between beneficial vs. harmful health behaviors, between health behaviors requiring much vs. little time and effort, and between health behaviors that are sensitive to changes in levels of overtime and work stress vs. behaviors that are less sensitive to such changes. This implies that future research cannot simply relate overtime to health or health behaviors in general: in order to enhance our understanding of the findings of such studies, researchers should attempt to specify the mechanisms accounting for these relations.

Practically, our findings suggest that working moderate levels of overtime (e.g., less than $5 \mathrm{~h}$ per week) does not entail a major risk to worker health. However, research shows that it is likely that health risks increase substantially when employees spend more time to working overtime [8], especially when their overtime work takes on a recurrent character. Thus, organizations should be aware of the degree to which their employees spend excessively much time to working overtime and, if necessary, they should take appropriate measures to reduce the work load of the workers involved (e.g., by hiring additional personnel). Further, our findings suggest that beneficial health behaviors may be more directly related to high levels of overtime than harmful behaviors. Whereas this is no reason to diminish the attention for workplace programs directed at smoking cessation or prevention of excessive alcohol use among overtime workers, it implies that it is good to make sure that especially overworkers have the opportunity to be physically active in their jobs (e.g., by implementing workplace activity programs, [35, 36]). Further, organizations could promote beneficial health behaviors by providing their employees with the opportunity to obtain healthy food and snacks in the workplace, e.g., during lunch breaks.
Open Access This article is distributed under the terms of the Creative Commons Attribution Noncommercial License which permits any noncommercial use, distribution, and reproduction in any medium, provided the original author(s) and source are credited.

\section{References}

1. Jacobs JA, Gerson K. The time divide: work, family, and gender inequality. Cambridge (MA): Harvard University Press; 2004.

2. Parent-Thirion A, Macias EF, Hurley J, Vermeylen G. Fourth European working conditions survey. Dublin: European Foundation for the Improvement of Working and Living Conditions; 2007.

3. Stier H, Lewin-Epstein N. Time to work: a comparative analysis of preferences for working hours. Work Occup. 2003;30:302-26.

4. Caruso CC. Possible broad impacts of long work hours. Indus Health. 2006;44:531-6.

5. Caruso CC, Hitchcock EM, Dick RB, et al. Overtime and extended work shifts: recent findings on illnesses, injuries, and health behaviors. Cincinnati $(\mathrm{OH})$ : National Institute of Health and Human Services (NIOSH); 2004.

6. Sparks K, Cooper C, Fried Y, Shirom A. The effects of hours of work on health: a meta-analytic review. J Occup Organ Psychol. 1997;70:391-408.

7. Spurgeon A, Harrington JM, Cooper CL. Health and safety problems associated with long working hours: a review of the current position. Occup Environ Med. 1997;54:367-75.

8. Van der Hulst M. Long workhours and health. Scand J Work Environ Health. 2003;29:171-88.

9. Beckers DGJ. Overtime work and well-being: opening up the black box. Nijmegen: Radboud University Nijmegen; 2008.

10. Siegrist J, Rödel A. Work stress and health risk behavior. Scand J Work Environ Health. 2006;32:473-81.

11. Meijman TF, Mulder G. Psychological aspects of workload. In: Drenth PJD, Thierry H, de Wolff CJ, editors. Handbook of work and organizational psychology. Hove: Psychology Press; 1998. p. 5-33.

12. Lundberg U, Frankenhaeuser M. Pituitary-adrenal and sympathetic-adrenal correlates of distress and effort. J Psychosom Res. 1980;24:125-30.

13. McEwen BS. Stress, adaptation, and disease: allostasis and allostatic load. Ann NY Acad Sci. 1998;840:33-44.

14. Geurts SAE, Sonnentag S. Recovery as an explanatory mechanism in the relation between acute stress reactions and health impairment. Scand J Work Environ Health. 2006;32:482-92.

15. De Bloom J, Kompier M, Geurts S, et al. De we recover from vacation? Meta-analysis of the effects of vacation on health and well-being. J Occup Health. 2009;51:13-25.

16. Rau R, Triemer A. Overtime in relation to blood pressure and mood during work, leisure, and night time. Soc Indic Res. 2004;67:51-73

17. Lynch JW, Kaplan GA, Cohen RD, et al. Do cardiovascular risk factors explain the relation between socioeconomic status, risk of all-cause mortality, and acute myocardial infarction? Am J Epidemiol. 1996;144:934-42.

18. Lallukka T, Lahelma E, Rahkonen O, et al. Associations of job strain and working overtime with adverse health behaviors and obesity: evidence from the Whitehall II Study, Helsinki Health Study, and the Japanese civil servants study. Soc Sci Med. 2008;66:1681-98.

19. Oliver G, Wardle J, Gibson EL. Stress and food choice: a laboratory study. Psychosom Med. 2000;62:853-65.

20. Oliver G, Wardle J. Perceived effects of stress on food choice. Physiol Behav. 1999;66:511-5. 
21. Schneider S, Becker S. Prevalence of physical activity among the working population and correlation with work-related factors: results from the first German National Health Survey. J Occup Health. 2005;47:414-23.

22. Steptoe A, Wardle J, Lipsey Z, et al. A longitudinal study of work load and variations in psychophysiological well-being, cortisol, smoking, and alcohol consumption. Ann Behav Med. 1998;20:84-91.

23. Ybema JF, Sanders J, De Vroome E. Cohortstudie arbeid, verzuim en gezondheid $(A V G)$ [Cohort study on employment, absence and health]. Hoofddorp: TNO Quality of Life; 2006.

24. Ybema JF, Van den Bos K. Effects of organizational justive on depressive symptoms and sickness absence: a longitudinal perspective. Soc Sci Med. 2010;70:1609-17.

25. Van Meurs L, Van Ossenbruggen R, Nekkers L. Rotten apples? Checking the quality of response behavior in the Intomart GfK online panel [in Dutch]. In Bronner AE, Dekker P, De Leeuw E, et al. editors. Ontwikkelingen in het marktonderzoek: Jaarboek Marktonderzoekassociatie. Haarlem: Spaarenhout; 2009. 34: 61-82.

26. Gezondheidsraad. Directions on food consumption 2006 [in Dutch]. The Hague: Gezondheidsraad; 2006

27. Jöreskog KG, Sörbom D. LISREL-8.30 [computer program]. Chicago: Scientific Software, 1999.

28. Karasek R, Brisson Ch, Kawakami N, et al. The Job Content Questionnaire (JCQ): an instrument for international comparative assesments of psychological job characteristics. J Occup Health Psychol. 1998;3:322-95.
29. Byrne BM. Structural equation modeling with AMOS. Mahwah: Erlbaum; 2009.

30. Chen WQ, Wong TW, Yu ITS. Association of occupational stress and social support with health-related behaviors among Chinese offshore oil workers. J Occup Health. 2008;50:262-9.

31. Taris TW, Kompier MAJ. Games researchers play: extreme groups analysis and mediation analysis in longitudinal occupational health research. Scand J Work Environ Health. 2006;32:463-72.

32. Johnson W, Krueger RF. The psychological benefits of vigorous exercise: a study of discordant MZ twin pairs. Twin Res Hum Genet. 2007; 10:275-83.

33. Zapf D, Dormann C, Frese M. Longitudinal studies in organizational stress research: a review of the literature with reference to methodological issues. J Occup Health Psychol. 1996;1:145-69.

34. De Lange AH, Taris TW, Kompier MAJ, et al. The relationships between job characteristics and mental health: examining normal, reversed and reciprocal relationships in a 4-wave study. Work Stress. 2004;18:149-66.

35. Proper KI, Hildebrandt V, Van der Beek AJ, et al. Effect of individual counseling on physical activity fitness and health: a randomized controlled trial in a workplace setting. Am J Prev Med. 2003;24:218-26.

36. Von Thiele Schwarz U, Lindfors P, Lundberg U. Health-related effects of worksite interventions involving physical exercise and reduced workhours. Scand J Work Environ Health. 2008;34:179-88. 